Pragmatics 8:2.221-237.

International Pragmatics Association

DOI: $10.1075 /$ prag.8.2.10min

\title{
INSTITUTIONAL TALK IN REFERRAL MEETINGS ${ }^{1}$
}

\author{
Wilma Minoggio
}

\section{Introduction}

Historically, the phenomenon of school failure coincided with compulsory education. The introduction of compulsory schooling brought about the problem of those pupils who were not able or did not want to conform to the pre-established rules of the school system.

In this article, neither do I want to discuss the different explanations which have been offered to account for this phenomenon, nor do I intend to investigate the various solutions subsequently suggested to deal with it. In order to sketch the scenario of the study underlying this paper, I will confine myself to a few remarks concerning the placement of pupils with learning disabilities into special education programs in Ticino (the Italian speaking part of Switzerland).

Ticino's educational policy tries to avoid educational stratification and to support the integration of pupils with learning and/or behavioral problems into the regular school system. The main objective of this policy is that of retaining the largest possible number of pupils within the regular classroom and, consequently, of supporting the interaction of variously gifted children. Accordingly, the educational system has taken on the responsibility for school failure and has, in order to face the problem effectively, created a complementary educational resource, the Pedagogical Support Service. ${ }^{2}$

"The Pedagogical Support Service is an internal institution of pre-school and elementary school". ${ }^{3}$ It aims at "supporting to the highest possible degree the development of the academic skills of pupils with learning disabilities in order to help them to attain the goals foreseen by the regular curriculum". This means that, although placed in a

${ }^{1}$ The study presented in this article was made possible through a grant from the Swiss National Research Foundation (FNRS) (National Research Program 33 "The Effectiveness of our Educational Systems", grant 4033-35848 attributed to M. L. Schubauer-Leoni; M. Grossen; F. Vanetta; W. Minoggio). I am especially indepted to Alberto Wohlgemuth for his support while the study was in progress and I would like to express my gratitude to all the teachers, pedagogical support teachers, parents and pupils for their cooperation in the gathering of the data. I also would like to thank Elisabetta Terrasi for having translated this text.

2 The Pedagogical Support Service of the primary school employs about one hundred professionals who take care of pupils with learning disabilities - about $12-13 \%$ of the pupils.

${ }^{3}$ The quotations are taken from the Regulations of the Pedagogical Support Service of the State Council of the Republic and Canton Ticino, 15th of May 1985 ( $\$ 9.1$ and $\S 9.5)$. All the quotations from Italian or French works have been translated into English. 
pedagogical support program, the pupil is maintained in the regular classroom but has to attend a few hours per week of individual teaching. The institutional representatives of this service have different types of training and perform different tasks. ${ }^{4}$ In this context, only the role of the pedagogical support teacher should be dwelled on. Basically, the role of the pedagogical support teacher is one of teaching, ${ }^{5}$ although this institutional task may be carried out by trained psychologists. Nevertheless, the responsibility for the pupil with learning disabilities is taken on by the regular classroom teacher, although he or she may count on the support of the Pedagogical Support Service.

Moreover, it is necessary to point out that, once a pupil has been assessed as learning disabled by the classroom teacher, the intervention of the Pedagogical Support Service cannot take place without the approval of the parents. ${ }^{6}$ Referral meetings are institutionalized meetings during which the classroom teacher presents the pedagogical support teacher, the parents and, in some cases, others (pupil, language teacher, etc.) with the evidence that made him or her consider the necessity of an intervention by the Pedagogical Support Service. It is on this occasion that the parents are asked to express their opinion about the problem raised by the classroom teacher and whether or not they agree to the placement of their child in a pedagogical support program. Parental permission constitutes the conditio sine qua non for the intervention as well as the basis for a more thorough discussion of the case and the exploration of different options of intervention (development of an individualized education plan).

\section{Objectives and theoretical background}

The aim of the study presented in this paper is to analyse the interactive dynamics in meetings between educators and parents and the practices of intervention of the Pedagogical Support Service from a micro-systemic perspective. It examines all the meetings concerning seven pupils with learning disabilities which take place over an academic year.

This article focuses on the interactional analysis of the first of these meetings, i.e. the referral meetings. A close examination of these first meetings aims at understanding how, during these particular kinds of interactions, the various parties establish common discussion subjects and negotiate their meaning. The study is guided by the following topics of investigation:

${ }^{4}$ Each Pedagogical Support Service team consist of: a) an educational psychologist leading the team; b) speech therapists; c) psychomotricians; d) pedagogical support teachers" (§11.1 ibidem).

${ }^{5}$ One of the main duties of a pedagogical support teacher is that of "working out an educational plan ( $\$ 18$ ibidem), which means that he or she does not have to perform any therapeutic task.

${ }^{6}$ At the time of the carrying out of this research project (1994-96) several committees were working on the new pre-school, elementary school and Pedagogical Support Service curriculum. The new curriculum came into force in September 1996 and has introduced some substantial changes concerning the parental participation in the discussion about the intervention of the Pedagogical Support Service. As a matter of fact the position of the parents has been weakened. 
- Which thematic contents are introduced? How are they developed, altered and abandoned during these meetings?

- How is the problem defined? How is its definition negotiated? To what extent can a common definition of the problem be reached?

-What kind of relationship exists between the definition of the problem negotiated during the meeting and the type of intervention suggested?

- What are the roles of the different participants during the interaction?

- Beyond the peculiarities characterising each situation, is it possible to observe a typical pattern for this kind of interaction?

In order to answer these questions, we carried out a discourse analysis which was aimed firstly at identifying the thematic contents which were discussed and secondly at accounting for the interactional dynamics, namely for the way in which these thematic contents were introduced and taken up throughout the meetings. Both these fields of research are characterised by a great heterogeneity regarding theoretical issues as well as methods of analysis, data and objectives. Attention was mainly paid to the development of a methodological frame in which the two levels of analysis merge. As a matter of fact, this study has a double objective. On the one hand, it focuses on the contents which are typical for referral interactions, on the other, it assumes that these contents can only be understood within the frame of the interpersonal dynamics established during the meeting itself.

Referral meetings may be considered as conversations during which the various participants, according to their role and position, have their own perception and interpretation of the matters under discussion, without necessarily focusing their attention on the same aspects of the problem. "Briefly, this type of meeting may be defined as a social practice that: a) is mediated by certain symbols, especially linguistic ones; b) takes place in a socially and institutionally organized interpersonal situation; c) risks being defined in different ways by the various participants; d) aims at negotiating and constructing a definition of the problem at hand" (Grossen 1996: 6). In this specific type of meetings, the aim is also to identify different options of intervention.

In this article, I will confine myself to presenting the methodology developed for this study, pointing out the problems encountered and some of the solutions suggested for them.

\section{The corpus}

The gathering of the data took place during the academic year 1994/95 and involved seven elementary school pupils. As soon as a classrom teacher had noticed the learning disabilities of a pupil and had asked for the intervention of the Pedagogical Support Service (PSS), the research team contacted the persons who were going to participate in the meeting. Once the permission to take part in the meeting and to record it was obtained for seven cases, the search for informants was halted.

Table 1 shows who participated in the seven referral meetings, where they took place and how long they lasted. 
I must point out that there was no information at our disposal either about the way the referral meetings had been arranged or about the aspects of the case previously discussed between the classroom teacher (CRT) and the parents (MOT/FAT) or between the classroom teacher and the pedagogical support teacher (PST) (see Appendix 1 for the list of abbreviations).

The regular participation of the members of the research team in the meetings and the information gathered by their observation enabled us to gain a sense of how the setting was established. The meetings were tape-recorded and fully transcribed according to the transcription conventions ${ }^{7}$ given in Appendix 2.

Table 1: Informations about the seven referral meetings

\begin{tabular}{|l|l|l|l|}
\hline \multicolumn{1}{|c|}{ Case } & \multicolumn{1}{|c|}{ Participants } & \multicolumn{1}{c|}{ Place } & \multicolumn{1}{c|}{ Duration } \\
\hline Case PAT & $\begin{array}{l}\text { Classroom teacher, teacher, pedagogical } \\
\text { support teacher, mother, researcher }\end{array}$ & PSS room & $43^{\prime} 00^{\prime \prime}$ \\
\hline Case LAM & $\begin{array}{l}\text { Classroom teacher, pedagogical support } \\
\text { teacher, mother, father, pupil, researcher }\end{array}$ & classroom & $45^{\prime} 25^{\prime \prime}$ \\
\hline Case ZVE & $\begin{array}{l}\text { Classroom teacher, pedagogical support } \\
\text { teacher, mother, pupil, researcher }\end{array}$ & classroom & $25^{\prime} 10^{\prime \prime}$ \\
\hline Case PAO & $\begin{array}{l}\text { Classroom teacher, pedagogical support } \\
\text { teacher, mother, pupil, researcher }\end{array}$ & PSS room & $30^{\prime} 10^{\prime \prime}$ \\
\hline Case FIL & $\begin{array}{l}\text { Classroom teacher, pedagogical support } \\
\text { teacher, teacher, mother, language-teacher, } \\
\text { researcher }\end{array}$ & classroom & $30^{\prime} 10^{\prime \prime}$ \\
\hline Case ANT & $\begin{array}{l}\text { Classroom teacher, pedagogical support } \\
\text { teacher, mother, researcher }\end{array}$ & classroom & $22^{\prime} 10^{\prime \prime}$ \\
\hline Case MAT & $\begin{array}{l}\text { Classroom teacher, pedagogical support } \\
\text { teacher, mother, pupil, researcher }\end{array}$ & PSS room & $57^{\prime} 30^{\prime \prime}$ \\
\hline
\end{tabular}

\section{The unit of analysis}

As already mentioned, at a methodological level, we develop appropriate tools in order to follow the thematic evolution of certain contents.

Given the large amount of data available, a unit of analysis had to be selected which would enable us to work on the whole corpus. Consequently, the first step of the analysis was to identify the different thematic categories treated in the referral meetings in order to be able, in a second step, to examine common patterns in the seven referral meetings.

The corpus was subdivided into episodes according to Van Dijk's (1982:178) definition of the term: "Episodes appear to be linguistically and psychologically relevant

7 It is obvious that the choice of working on transcripts of verbal interactions involves a decontextualization of the corpus with regard to the real contexts in which the conversations took place (Galimberti 1992). Paraverbal and non-verbal elements which, during the interaction, participate in the constitution of meaning are in fact missing. I am very much aware of the fact that transcripts "... are still an artefact and have a subjective dimension - transcrittore/traditore. A fact which, however, does not have to be dramatised beyond measure" (Kebrat-Orecchioni 1990: 70, our translation). 
units of discourse structure and processing. They are taken as semantic units, which can be defined as sequences of propositions of a text which can be subsumed under a macroproposition".

One of the distinctive features of an episode is that of maintaining its autonomy while simultaneously being part of a larger structure. It displays an internal coherence due to the strict succession of the turns devoted to a same thematic content. Each episode can therefore be qualified by a theme, a semantic unit which allows the identification of the contents of the interaction. The definition given to the theme was general enough to include small variations in the way in which a given theme was topicalised.

Whereas in some cases linguistic markers (which facilitate the identification of semantic shifts or ruptures ${ }^{8}$ ) may be found in the transcript, in others the subdivision of the corpus into episodes is more problematical. It is at this stage that the researcher's interpretation activity comes into play. He or she "retrieves his or her knowledge about this type of situations, a knowledge which is not usually addressed by scholars, and which consists of a mixture of common sense, theoretical concepts, specific notions, familiarity with this type of situations and knowledge of what precedes and follows the analysed sequence" (Grossen \& Apothéloz 1996: 9). Due to possible divergent interpretations, the task of sectioning the corpus into episodes was entrusted separately to three researchers who came to a high level of agreement regarding the boundaries of the episodes.

\section{Quantitative analysis}

The subdivision into episodes enabled us to reduce the corpus to smaller units characterised by broad but well defined thematic categories. As could be easily foreseen, the thematic contents addressed are strictly related to the purpose of the referral meetings and, more generally, to the institutional frame in which the conversations took place. These thematic categories are:

- the reasons for referral (which also includes initiating the meeting, the request addressed to the Pedagogical Support Service and the stating of the pupil's difficulties);

- the definition of the problem (description and analysis of the learning disabilities of the pupil and the causes for his/her failure);

- enquiry about pupil's academic performance;

- $\quad$ enquiry about the child;

- development of different options of intervention;

- the Pedagogical Support Service;

- anecdote;

- epilogue.

${ }^{8}$ In our corpus, the formulation of direct or indirect questions, pauses and hesitation phenomena, expressions such as "so then", "well then", "I think", "according to my opinion" and topic shifts often coincide with the beginning of a new episode. 
As can be seen from this list, two categories ("anecdote" and "epilogue") do not refer to a specific content, but to a series of contents which can be labelled as "anecdotes", namely side issues or small talk not directly related to the pupil's difficulties, and "epilogues", namely closing or pre-closing sequences.

This classification provides a first hint of what is discussed during the referral meetings. It shows in particular that a limited number of thematic categories is discussed during the referral meeting. However, it does not supply any information about the importance of the single thematic content, its succession and the way it is discussed and developed.

Consequently, a quantification of the various thematic categories addressed in each of the seven analysed referral meetings was carried out. This first analysis shows the importance held by every topic in each of the seven cases (see table 2).

Table 2: Number of episodes devoted to each thematic categories

\begin{tabular}{lccccccc}
\hline & Case & Case & Case & Case & Case & Case & Case \\
& PAT & LAM & ZWE & PAO & ANT & FIL & MAT \\
\hline Reasons for referral (RR) & 2 & 3 & 2 & 1 & 2 & 3 & 5 \\
Definition of the problem (D) & 1 & 3 & 1 & 4 & 2 & 2 & 5 \\
Intervention (I) & 5 & 14 & 6 & 7 & 5 & 2 & 6 \\
Pedagical Support Service (PSS) & 1 & 2 & 2 & 1 & & 1 & 2 \\
Enquiry about the pupil (EAP) & 2 & 3 & & 1 & & 2 & 3 \\
Enquiry about the child (EAC) & 1 & 1 & 1 & 1 & 5 & 1 & 3 \\
Anecdote (A) & 1 & 1 & 1 & 1 & 1 & & 2 \\
Epilogue (E) & 2 & 1 & 1 & 1 & 1 & 1 & 1 \\
Total of episodes & & & & & & & \\
\hline
\end{tabular}

Table 2 shows that all the thematic categories which were determined were observed in almost all cases.

The choice of the episode as the unit of analysis decreases the importance of the variable "time devoted to each thematic category". Nevertheless, the latter provides some information about the importance of each thematic category within the various conversations (see table 3 ).

Table 3: Time devoted to each thematic category

\begin{tabular}{lrrrrrrr}
\hline & Case & Case & Case & Case PAO & Case & Case FIL & \multicolumn{1}{c}{ Case } \\
& PAT & \multicolumn{1}{c}{ LAM } & ZWE & & ANT & & MAT \\
\hline RR & $6^{\prime} 00^{\prime \prime}$ & $3^{\prime} 20^{\prime \prime}$ & $2^{\prime} 35^{\prime \prime}$ & $1^{\prime} 45^{\prime \prime}$ & $5^{\prime} 55^{\prime \prime}$ & $3^{\prime} 35^{\prime \prime}$ & $14^{\prime} 30^{\prime \prime}$ \\
D & $3^{\prime} 55^{\prime \prime}$ & $6^{\prime} 55^{\prime \prime}$ & $2^{\prime} 25^{\prime \prime}$ & $8^{\prime} 30^{\prime \prime}$ & $4^{\prime} 15^{\prime \prime}$ & $1^{\prime} 00^{\prime \prime}$ & $5^{\prime} 40^{\prime \prime}$ \\
I & $0^{\prime} 40^{\prime \prime}$ & $26^{\prime} 40^{\prime \prime}$ & $11^{\prime} 10^{\prime \prime}$ & $14^{\prime} 40^{\prime \prime}$ & $6^{\prime} 05^{\prime \prime}$ & $5^{\prime} 15^{\prime \prime}$ & $16^{\prime} 45^{\prime \prime}$ \\
PSS & $5^{\prime} 25^{\prime \prime}$ & $1^{\prime} 00^{\prime \prime}$ & $2^{\prime} 30^{\prime \prime}$ & $0^{\prime} 35^{\prime \prime}$ & $0^{\prime} 40^{\prime \prime}$ & $0^{\prime} 00^{\prime \prime}$ & $4^{\prime} 45^{\prime \prime}$ \\
EAP & $1^{\prime} 30^{\prime \prime}$ & $2^{\prime} 10^{\prime \prime}$ & $0^{\prime} 00^{\prime \prime}$ & $0^{\prime} 35^{\prime \prime}$ & $2^{\prime} 05^{\prime \prime}$ & $0^{\prime} 00^{\prime \prime}$ & $5^{\prime} 55^{\prime \prime}$ \\
EAC & $2^{\prime} 25^{\prime \prime}$ & $0^{\prime} 15^{\prime \prime}$ & $1^{\prime} 30^{\prime \prime}$ & $0^{\prime} 25^{\prime \prime}$ & $5^{\prime} 35^{\prime \prime}$ & $10^{\prime} 05^{\prime \prime}$ & $4^{\prime} 55^{\prime \prime}$ \\
A & $3^{\prime} 45^{\prime \prime}$ & $1^{\prime} 20^{\prime \prime}$ & $2^{\prime} 20^{\prime \prime}$ & $1^{\prime} 00^{\prime \prime}$ & $0^{\prime} 00^{\prime \prime}$ & $1^{\prime} 40^{\prime \prime}$ & $3^{\prime} 20^{\prime \prime}$ \\
E & $1^{\prime} 15^{\prime \prime}$ & $3^{\prime} 45^{\prime \prime}$ & $2^{\prime} 40^{\prime \prime}$ & $2^{\prime} 40^{\prime \prime}$ & $2^{\prime} 35^{\prime \prime}$ & $0^{\prime} 35^{\prime \prime}$ & $1^{\prime} 40^{\prime \prime}$ \\
& & & & & & & \\
Total & & & & & & & \\
\hline
\end{tabular}


Tables 2 and 3 show that the thematic categories concerning the definition of the problem, the reasons for referral and the options of intervention are more important than the others. Moreover, beyond the particularity of each case, a common aspect may be noted: the thematic category "intervention" has the most important position in all referral meetings. Thus, the discussion seems to concern the invervention to be carried out (in particular the reason for referral and the definition of the problem) more than the investigation of pupil's learning disabilities.

In order to identify the pattern of the thematic development, a sequential analysis, which enabled us to chart the succession of the various thematic contents in the seven cases was carried out. Since no predetermined institutional procedure exists for referral meetings, one would expect a non-linear thematic development, characterised by digressions, as well as a superimposition of new and given elements due to the emphasis on a given thematic contents, all of it related to the interpersonal dynamics established during the interaction.

Charts 1 and 2 show the thematic categories, their succession and the time devoted to them during the interactions of two of the seven analysed cases (PAT and LAM).

Chart 1: The sequence of thematic categories, Case PAT

\begin{tabular}{l|l|l|l|l|l|l|l|l|l|l|l|l|l|l|l|l|l|l|l|l|l|l|l|l|l|l|l|l|l|}
\hline MIN & 2 & 4 & 6 & 8 & 10 & 12 & 14 & 16 & 18 & 20 & 22 & 24 & 26 & 28 & 30 & 32 & 34 & 36 & 38 & 40 & 42 & 44 & 46 & 48 & 50 & 52 & 54 & 56 & 581 \\
\hline
\end{tabular}

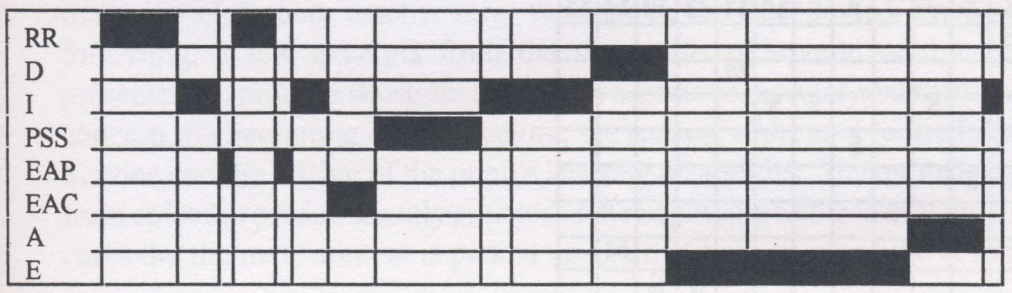

Chart 2: The sequence of thematic categories, Case LAM

\begin{tabular}{ll|l|l|l|l|l|l|l|l|l|l|l|l|l|l|l|l|l|l|l|l|l|l|l|l|l|l|l|l|}
\hline MIN & 2 & 4 & 6 & 8 & 10 & 12 & 14 & 16 & 18 & 20 & 22 & 24 & 26 & 28 & 30 & 32 & 34 & 36 & 38 & 40 & 42 & 44 & 46 & 48 & 50 & 52 & 54 & 56 & 58 \\
\hline
\end{tabular}

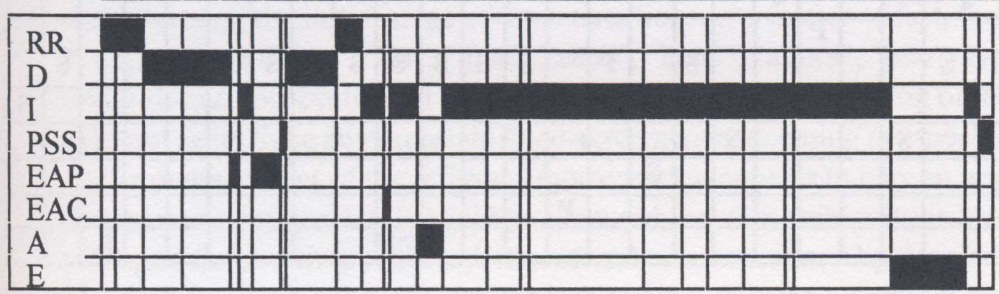

The analysis of the sequences observed in the seven cases shows that the thematic development of the referral meeting seems to follow a hidden agenda. In fact, the thematic 
categories appear at specific times and in a particular succession: reason for referral; description of the pupil's learning disabilities; options for intervention, and epilogue.

At this stage of the analysis, we moved to a second level of analysis involving the dimension of interactive dynamics. More precisely, we tried to determine who, among the participants was responsible for the switch from one episode to the next. As a matter of fact, it is generally acknowledged that the speaker who initiates the conversation and introduces the episodes is able to determine the general development of the interaction (Kerbrat-Orecchioni 1992). This is a first clue, among others, ${ }^{9}$ indicating the position of the various participants in referral meetings. However, it must be pointed out that the participant who causes the switch from one thematic content to the next is not necessarily the participant who initiates the new episode. In most cases, the identification of the keyspeaker is facilitated by the presence of questions and reformulations, since thematic contents are picked up again, but in others, it is left again to the researcher's interpretation to find out who is controlling the development of the interaction.

Charts 3 and 4 show who, among the participants, is responsible for the shaping of the interaction in the two cases already referred to in charts 1 and 2 and how the various thematic categories are switched to and fro. In charts 3 and 4 the subdivision into episodes has been preserved, whereas the duration of the latter has been omitted.

Chart 3: Thematic categories and participants, Case PAT ( $\mathrm{S}=\mathrm{PST}, \mathrm{M}=\mathrm{MOT})$

\begin{tabular}{|c|c|c|c|c|c|c|c|c|c|c|c|c|c|c|c|}
\hline & 11 & 2 & 3 & 4 & 5 & 6 & 7 & 8 & 9 & 10 & 11 & 12 & & $4[1$ & 15 \\
\hline$R R$ & S1 & & & S & & & & & & & & & & & \\
\hline$D$ & & & & & & & & & & & $\mathbf{M}$ & & & & \\
\hline I & & $\mathbf{M}$ & & & & $\mathbf{S}$ & & & S & S & & & & & S \\
\hline PSS & & & & & & & & $\mathbf{S}$ & & & & & & & \\
\hline EAP & & & $\mathbf{S}$ & & $\mathbf{S}$ & & & & & & & & & & \\
\hline EAC & & & & & & & S & & & & & & & & \\
\hline A & & & & & & & & & & & & & & n & \\
\hline E & & & & & & & & & & & & $\mathbf{S}$ & $\mathbf{S}$ & & \\
\hline
\end{tabular}

Chart 4: Thematic categories and participants, Case LAM ( $\mathrm{S}=\mathrm{PST}, \mathrm{T}=\mathrm{CRT}, \mathrm{P}=\mathrm{FAT})$

\begin{tabular}{|c|c|c|c|c|c|c|c|c|c|c|c|c|c|c|c|c|c|c|c|c|c|c|c|c|c|c|c|c|}
\hline & 1 & 2 & 3 & 4 & 5 & 6 & 7 & 8 & 9 & 10 & 11 & 12 & 13 & 14 & 15 & 16 & 17 & 18 & 19 & 20 & 21 & 22 & 23 & 24 & & 26 & 27 & 28 \\
\hline PR & $\mathbf{T}$ & $\overline{\mathbf{P}}$ & & & & & & & & $\mathbf{S}$ & & & & & & & & & & & & & & & & & & \\
\hline D & & & S & $\mathbf{S}$ & & & & & $\overline{\mathbf{P}}$ & & & & & & & & & & & & & & & & & & & \\
\hline I & & & & & & S & & & & & & $\mathbf{S}$ & & $\mathbf{P}$ & & $\mathbf{S}$ & $\mathbf{S}$ & $\mathbf{S}$ & $\mathbf{S}$ & $\mathbf{S}$ & $\mathbf{S}$ & $\mathbf{S}$ & $\mathbf{S}$ & $\mathbf{S}$ & $\mathbf{S}$ & & $\mathbf{S}$ & \\
\hline PSS & & & & & & & & $\mathbf{P}$ & & & & & & & & & & & & & & & & & & & & $\mathbf{S}$ \\
\hline EAP & & & & & $\mathbf{S}$ & & S & & & & $\mathbf{S}$ & & & & & & & & & & & & & & & & & \\
\hline EAC & & & & & & & & & & & & & $\mathbf{S}$ & & & & & & & & & & & & & & & \\
\hline A & & & & & & & & & & & & & & & $\mathbf{P}$ & & & & & & & & & & & & & \\
\hline E & & & & & & & & & & & & & & & & & & & & & & & & & & $\mathbf{S}$ & & \\
\hline
\end{tabular}

${ }^{9}$ Two further aspects were considered: the degree of participation in the discussion, measured by the number of characters needed to transcribe the turns of each participant and the operations of textualisation (see Cosnier and Kerbrat-Orecchioni, 1987) which give an idea of the share of each participant in the shaping of the conversation. 
This type of analysis approaches the corpus from a purely quantitative perspective. It is nonetheless interesting since it shows that the institutional role of the participants determines, at least in part, the characteristics and the position of their contributions to the conversation. In both cases, the pedagogical support teacher introduces a new thematic content more often than do the other participants. The same has been observed in the five other cases.

These analyses brought to light the need for a more thorough examination of the thematic contents and the interactional dynamics in the seven cases. As a consequence, a qualitative analysis was carried out, in order to gain a better insight into the way in which the thematic contents are discussed, interpreted, developed and negotiated during the interactions.

\section{Qualitative analysis: The reasons for referral}

In this section I will confine myself to presenting the qualitative analysis concerning the thematic category "reasons for referral", since this paper dwells on methodological aspects.

The analysis of the thematic development showed that after the usual greetings and introductions, the discussion immediately started with the presentation of the reasons that made the classroom teacher refer the case to the Pedagogical Support Service. In the following, a few excerpts from the transcripts of several of the meetings ${ }^{10}$ will be presented, in order to illustrate the salient aspects of the analysed thematic category. They concern the beginning of the meeting, the request addressed to the Pedagogical Support Service and the stating of the pupil's learning disabilities. The quoted sequences are taken from episodes predominantly situated at the beginning of the interaction, although in some cases the thematic content is picked up again at later stages of the conversation.

\subsection{The beginning of the meeting}

Let us first examine who initiates the discussion. Excerpt 1 is situated at the very beginning of the meeting. Both excerpts 1 and 2 show the embarassment and the hesitations characterising the initial stage of the interaction. As a matter of fact, the first turns consist of expressions ("well", "so", "then"/ "ecco", "bene", "allora", "bon") typically used in the Swiss Italian context to start a conversation. At the very beginning of the interaction there does not seem to be any preestablished agreement concerning the speaker who should take on the management of the referral. Improvisation appears to play an important role, a fact that causes a jerky start. It could be ventured that this ambiguity is brought about by the setting of the meeting. Although the referral was summoned by the classroom teacher, the place where the meeting takes place is not necessarily the classroom but, in some cases, a room of the Pedagogical Support Service. This is probably the reason why sometimes it is

\footnotetext{
10 The original transcription numeration of the turns was kept in the excerpts in order to give an idea of where the quoted passage is situated in the conversation.
} 
the pedagogical support teacher who takes the initiative in starting the discussion either by addressing issues which concern his or her own task or by urging the other participants to speak.

\section{(1) Case PAT}

1. PST: $\quad$ well

2.

3. CRT:

4. PST:

5. CRT:

hmh
(6 sec. pause)

well then so we are now meeting and I would like to know how this request came about whether it was requested by the mother or by the teacher ...

we asked for it . we asked for it we who . at the beginning of the year the first week we were all here and we saw that she had some difficulties...

\section{Original transcript in Italian}

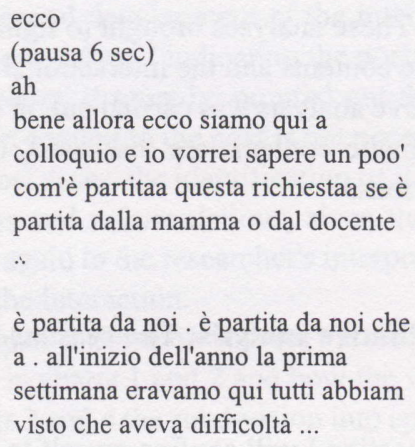

Original transcript in Italian

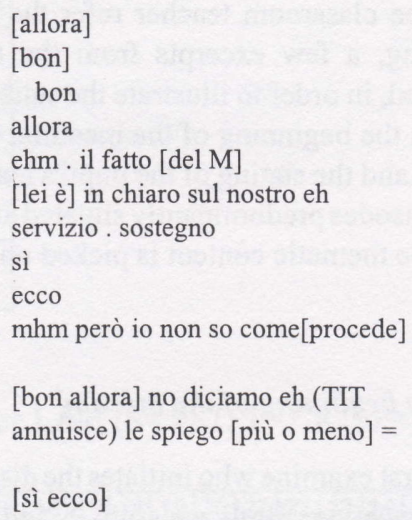

Among the analysed cases, another way of starting the discussion was found, as shown in excerpt 3 , where the classroom teacher presents a previously prepared document (which the mother is supposed to know) to account for the pupil's academic performance and justify the reasons that made her call upon the Pedagogical Support Service. This procedure favours the immediate beginning of the conversation and informs the participants about the details of the situation.

In other cases, the initial malaise is overcome by reformulating questions asked by the parents at the very beginning of the meeting: "so Mrs. XY asked me ... whether she is intelligent", "then L's father asked me what the problems were". These questions seem to be used by the classroom teacher as a pretext for initiating the interaction. 
(3) Case PAO

1. CRT: so I brought a few documents anyway you have already seen all of them haven't you? the dictations

2. (PST calls the child MOT tells him to take a seat)

3. CRT: so .. then I noticed that $P$ has understood how writing and reading work or rather he understood the mechanisms but he is confused about certain letters ...

\section{Original transcript in Italian}

ecco io ho portato un po' di documenti comunque son tutte cose che lei ha già visto no ii dettati

(OSSP chiama il bambino la MADRE gli indica un posto a sedere)

ecco .. allora io ho notato appunto che il $\mathrm{P}$ ha capito bene come funziona la scrittura e la lettura cioè il meccanismo lui l'ha capito bene però lui fa delle confusioni per ciò che riguarda determinate lettere.....

\section{2. The request addressed to the PSS}

Referral meetings are stricly motivated by the classroom teacher requiring the pupil's placement into a pedagogical support program. In fact, in all the analysed cases, the referral was made by the classroom teacher. ${ }^{11}$ A particular importance is therefore attached to his or her contributions as well as to his or her position. It must be emphasized that, in most of the cases, the classroom teacher addresses right from the start the most problematical aspects of the pupil's academic performance, as the following excerpts show:

(4) Case ZVE

5. CRT: we all saw that she found it difficult to add . additions and subtractions and so on and she seemed to confuse only the figures one thousand five hundred maybe she wrote fifteen now I am exaggerating it $[$ no but $]=$

\section{MOT: [yes yes]}

7. $\mathrm{CRT}$ : = she wrote everything wrong and she also used to disturb the class she didn't pay attention $[\ldots]=$

\section{Original transcript in Italian}

tutti abbiam visto che aveva difficoltà . nel fare somme no nel fare addizioni e sottrazioni e così e sembrava che avesse una certa confusione solo sui numeri cioè magari . mille cinquecento magari scriveva quindici adesso esagero [no ma] $=$

[sì sì] = scriveva tutto sbagliato ee $\mathrm{e}$ aveva anche il problema del disturbo in classe era un po' così . disattenta $[.]=$.

${ }^{11}$ Although the parents and the pupil may also ask for the intervention of the Pedagogical Support Service, several surveys (Minoggio 1991; Mossi 1997) have shown that in most of the cases this is done by the classroom teacher. 
(5) Case LAM

1. CRT: so L's dad asked me what the problems were what. Itold him that we did these tests at the beginning of the year you did them she did them . and there proved to be some difficulties so ...

(6) Case FIL

1. CRT: I already explained it was about $\mathrm{A}$ - (mother nods) I have the impression that she got stuck. hm she got stuck at a certain point and now she finds the next step very difficult

2. MOT: hmh. [she can't take it]

\section{Original transcript in Italian}

ecco il papà del $\mathrm{L}$ mi aveva chiesto un poo' quali erano i problemi cosa . io gli ho detto che abbiamo fatto queste prove all'inizio le hai fatte tu le ha fatte lei e sono. ed è risultato che c'erano delle difficoltà ecco...

\section{Original transcript in Italian}

ho già spiegato era per l'A . (MADRE annuisce) a mee da un po' l'impressione che si è che si è fermata un po' ai box . eh si è fermata ad un certo punto e quello scalino in piùu adesso ha grosse difficoltà $\mathrm{mhm}$. [non ci riesce a fare]

Excerpts 4, 5 and 6 clearly show that the classroom teacher's discourse focuses right from the start on the pupil's "problems", "difficulties", "mistakes" and supplies a portrait of the child characterised by what he or she is not able to do.

During the presentation of the reasons for referral, one of the classroom teachers provides a different image of the pupil by underlining, in the first place, positive features and improvements and integrating the difficulties into a more ample discourse. This is presented in excerpt 7.

\section{(7) Case ZVE}

1. CRT: $\quad$... so then I told her look she is such a good girl she really is . because she wants to work her diligence should be praised really because nobody could do more $\mathrm{xxx}$ there are only we saw some problems with letters have been overcome xxx she worked so hard during the holidays she read she prepared herself and there I was really satisfied we still have some problems with figures (MOT nods) that's why ...
Original transcript in Italian

...ecco allora le ho detto guardi che è una bambina che è d'oro veramente . perché ha una voglia di lavorare un impegno che sono veramentee encomiabili perché meglio di così non può fare $\mathrm{xxx}$ ci sono solo qualche abbiamo visto le difficoltà sulle letterine così sono state superate $\mathrm{xxx}$ ha avuto anche un buonissimo impegno durante le vacanze ha letto si è preparata bene e li veramente sono contento abbiamo poi ancora qualche difficoltà con i numeri (MADRE annuisce) ecco perché.... 
One might still wonder whether this way of introducing the matter, by speaking first of the pupil's virtues, should not also be considered a clue for the malaise caused by the discussion of the problem of school failure when the teacher has to face the parents and in some cases the pupil as well.

Leaving aside the manner in which the problem is addressed, it can be observed that the meetings always focus on the pupil and his or her difficulties. Only in one case does the referral appear also to be motivated by the classroom teacher questioning his work: "I could not understand the problem", "I would like to get some advice".

Considering that the pupil and his or her failure are the main issues under discussion, it is interesting to notice that these issues are often addressed in a generic and vague manner, sometimes enriched by some hints concerning what causes the difficulties: "she got stuck", "there were some difficulties", "no good at addition and subtraction", "some difficulties with figures", "confusion of letters". Thus, the discussion about the problem at issue appears rather vague; the information is concise and the examples are rare; this makes it quite difficult, at least at this stage of the interaction, to understand the real extent of the problem.

Another aspect that emerges from the analysis regards the use, by some of the speakers, of a plural or impersonal subject such as in: "we all saw", "we made", "we thought", "it was clear". A reason for this may be that the implication of other partners reduces the importance attributed to the diagnosis of school failure. But the use of a plural or impersonal subject could also be interpreted as a strategy to warrant the consensus among the different participants.

\subsection{The formulation of the pupil's difficulties}

The immediate introduction of the pupil's learning disabilities seems to justify the presence of the pedagogical support teacher and the intervention of the Service. As a matter of fact, the placement of the pupil into a pedagogical support program is immediately mentioned in the first turns, the classroom teacher trying to establish a link between the pupil's failure and the presence of the pedagogical support teacher. difficulties.

Excerpts 8, 9 and 10 show how the classroom teacher refers to the pupil's

\section{(8) Case ZVE}

1. CRT:
... we still have some problems with figures (MOT nods) that's why I said I asked also for the help of the PST who could work with her individually maybe even in a different atmosphere with other things with other teaching aids and so on ...
Original transcript in Italian

..... abbiamo poi ancora qualche difficoltà con i numeri (MADRE annuisce) ecco perché ho detto ho chiesto anche l'aiuto del MS che la può seguire da sola magari in un ambiente . anche un po' diverso dal nostro con altre cose con altri con altre possibilità di di di materiale eccetera... 
(9) Case PAO

3. CRT: $\quad$...he makes a mess with certain letters . so . and since the PST . has a spare hour. I would agree to hm having him helped by him I honestly at the moment I have very little time to devote to him really no $\cdots$
(10)

\section{Case ANT}

1. CRT: so then gi given the the problems of the girl we thought of asking the PST for some help the PST because for Italian she is already tutored by the language teacher one one lesson per week . and we still need something for mathematics no

\section{MOT:yes}

3. CRT: $=$ so then he decided to tutor her twice a week together with

4. PST: $[\mathrm{C}]$

\section{Original transcript in Italian}

... lui fa delle confusioni per ciò che riguarda determinate lettere . ecco . e visto che $\mathrm{M}$ ha un'ora di tempo . io sarei d'accordo di . mm farlo mettere a posto mettere a posto da lui perché io sinceramente adesso ho poco pochissimo tempo da deda dedicarli proprio no.....

Original transcript in Italian

ecco allora vis visto i i problemii dellaa ragazza abbiamo pensato di chiedere aiuto al maestro dii . al maestro di sostegno perché per l'italiano è già seguita dalla docente degli alloglotti unaa una lezione per settimana . e mancava un po' per la matematica no

si

= ecco allora lui ha deciso che la segue due volte alla settimana assieme la .

la [C]

As show these excerpts, the pedagogical support teacher is seen as the main resource in facing the problem, the one who will be set the task of "mending" the pupil since his intervention is conceived as one of repair.

From the way the classroom teacher introduces the subject it could be inferred (although we do not have any information) that there has already been a meeting between the classroom teacher and the pedagogical support teacher in which they have reached an agreement about the necessity and possibility of intervening. In this case the referral would take place to inform the parents about a decision already made, with the risk of reducing the value of the referral meeting and of jeopardizing the parents' active participation in the definition of the problem. As excerpt 11 shows, this procedure is not accepted by all the pedagogical support teachers. In fact, in one of the analysed cases, the pedagogical support teacher clearly stresses the fact that there are various options of negotiation among the different parties.

Depending on the situation, the pedagogical support teacher is introduced (or introduces himself or herself) by his or her name or as the representative of the Service. His or her role is not always explicit and when this issue is addressed, the pedagogical support 
teacher's function is primarily defined as that of "helping" the pupil. It should be stressed that the options of intervention of the Service are more often determined by institutional factors (availability of pedagogical support teachers) than by pedagogical reflections: "since the PST has a spare hour", "he tutors her twice a week together with C [another child's name], since there are no other available hours". As a matter of fact, external constraints significantly affect the pursuit of possible alternatives for intervention. The classroom teacher usually suggests one or two hours of tutorial per week irrespective of the type and the gravity of the problem and even before a common definition of the problem has been reached. The solution proposed at once by the classroom teacher to combat the learning disabilities of the pupil completly relies on the pedagogical support teacher.

(11)

\section{Case LAM}

1. CRT: $\quad$...it was noticed that there were some difficulties so and afterwards it was thought since there is the Pedagogical Support Service at school then you could LAM be tutored during hm I don't know how much it would be per week one hour? [per week then we have to decide]

2. PST: [but this has to be decided] decided together what we want to do first of all whether they feel the need

\section{Original transcript in Italian}

......è risultato che c'erano delle difficoltà ecco e dopoo si era pensato che visto che c'è il sostegno pedagogico a scuola che potresti $\mathrm{L}$ essere seguito durante ee non so quanto sarebbe la settimana un'ora? [per settimana dopo bisogna decidere]

[ma questo è da decidere] decidere assieme cosa vogliamo fare prima di tutto se loro sentono il bisogno

In a single case, the mother is involved in the measures suggested to improve the pupil's academic performance: "I think it is important that she should devote the child half an hour every day". Can we speak of delegation? Although this question cannot be answered at this stage of the analysis, it was observed that, generally, the classroom teacher does not participate actively in the solution of the problem. Instead he or she tends to rely upon the others. On the one hand, this attitude may surprise, since it is the classroom teacher who is responsible for the pupil. However, on the other hand, we could put forward the hypothesis that classroom teachers often experience a sense of failure and incapacity when they refer one of their pupils to the PSS.

The qualitative analysis presented in this section focused on the main reasons for referral. These issues are initially raised by the classroom teacher and then resumed and expanded upon by the various participants. Only a few of the numerous examples in the corpus have been quoted above, but the same type of qualitative analysis was carried out for all of the eight defined thematic categories.

\section{Conclusions}

After having determined the categories accounting for the thematic contents discussed in 
the seven referral meetings that have been analysed, we carried out a quantitative analysis showing the frequency and duration of each thematic category. We then presented a sequential analysis aimed at examining whether the thematic development followed certain patterns or routines. Finally, we examined who among the participants introduced a thematic content. In a subsequent analysis, we gave a closer look to the way in which a particular thematic category (namely the referral reasons) is discussed. These different types of analyses all tried to account for the thematic and interactional dynamics of each single meeting taken in its totality. One of the consequences of this basic choice is that the analyses which have been carried out remain rather broad and general. In the future, a more detailed analysis will be necessary to gain a better insight into other aspects of interactional dynamics and of theme management. It should also be pointed out that the referral meetings which have been analysed in this article were the first of a series which includes all the annual summary meetings concerning the seven cases (i.e. 13 per year) and several individual meetings with the institutional representatives. Further analyses should aim at contextualising these first meetings within the series to which they belong.

\section{References}

Brown, G. \& G. Yule (1986) Analisi del discorso.Bologna: Il Mulino.

Cosnier, J. \& C. Kerbrat-Orecchioni (1987) Décrire la conversation. Lyon: Presses Universitaires de Lyon.

Galimberti, C. (1992) Analisi delle conversazioni e studio dell'interazione psicosociale. In La conversazione. Prospettive sull'interazione psico-sociale. Milano: Guerini Studio.

Grossen, M. (1996) Counselling and gatekeeping: Definition of the problem and situation in a first therapeutic interview. Text 16.2: 101-132.

Grossen, M. \& D. Apothéloz (1996) Communicating about communication in a therapeutic interview. Journal of language and social psychology 15.2: 101-132.

Kerbrat-Orecchioni, C. (1990) Les interactions verbales, Tome I. Paris: Armand Colin.

Kerbrat-Orecchioni, C. (1992) Les interactions verbale, Tome II. Paris: Armand Colin.

Minoggio, W. (1991) Le rappresentazioni sociali del disadattamento scolastico: Opinioni dominanti nelle principali componenti scolastichenei confronti dei Servizi di sostegno pedagogico. Bellinzona: Dipartimento dell'Istruzione e della Cultura, divisione della scuola, USR (9109).

Mossi, G. (1997) Dati statistici relativi agli allievi seguiti dai servizi di sostegno pedagogico. Bellinzona: Dipartimento dell'Istruzione e della Cultura, divisione della scuola.

Van Dijk, T. (1982) Episode as units of discours analysis. In D.Tannen (ed.), Analysing discourse: Text and talk. Washington D.C: Georgetown University Press.

\section{Appendix 1: List of abbreviations}

PAT, LAM, ZWE, PAO, FIL, ANT, MAT, C

CRT

FAT pupils

classroom teacher

father 


MOT
PST
PSS
RR
D
I
EAP
EAC
A
E

mother

pedagogical support teacher

Pedagogical Support Service

reasons for referral

definition of the problem

intervention of the PSS

enquiry about the pupil

enquiry about the child

anecdote

epilogue

\section{Appendix 2: Transcription conventions}

[]
( )
.
..
(n sec. pause)
xxx
word=
=word
word
wo word
woooord
word

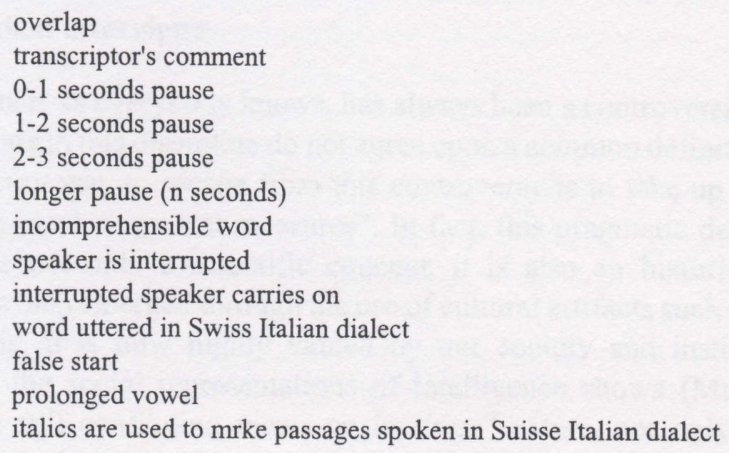

